\title{
ENSINO DE HISTÓRIA E RESISTÊNCIA: NOTAS SOBRE UMA HISTÓRIA MENOR
}

\author{
Nilton Mullet Pereira
}

\section{RESUMO}

Este artigo é resultado de uma reflexão teórica realizada a partir das entrevistas de dois professores, acerca do ensino de História na escola básica, enfatizando o conceito de história menor, como elemento teórico capaz de ler e compreender determinadas práticas de sala de aula que representam fissuras nos modos tradicionais de se ensinar História. O texto realiza um diálogo teórico com o conceito de simpatia de Bergson, a fim de pensar novas formas de se ensinar história e de subverter a temporalidade eurocentrada. Nesse sentido, também dialoga com a descolonialidade, no sentido de realizar a crítica tanto à história maior, quanto a temporalidade que lhe é correlata. $\mathrm{O}$ objetivo principal está em desenvolver o conceito de história menor e permitir que ele se torna uma chave de leitura para pensar o ensino de história desde uma perspectiva que rompe com as grandes explicações estruturais e que promove, na sala de aula, uma história de temas e sujeitos invisibilizados pela história maior.

Palavras-chave: Ensino de História; história menor; temporalidades

\section{ABSTRACT}

This article is the result of a theoretical reflection based on the interviews of two teachers about the teaching of History in elementary school, emphasizing the concept of a minor history as a theoretical element capable of reading and understanding certain classroom practices that represent loopholes in traditional ways of teaching History. The text carries out a theoretical dialogue with Bergson's concept of sympathy in order to think about new ways of teaching history and of subverting Eurocentred temporality. In this regard, it also dialogues with decoloniality, in the sense of criticizing larger history as well as the temporality that is related to it. The main objective is to develop the concept of minor history and to allow it to become a key reading to think about teaching history from a perspective that breaks with the great structural explanations and that promotes, in the classroom, a history of issues and individuals unseen by a larger history.

Keywords: Teaching History; minor history; temporalities 


\section{INTRODUÇÃO}

A História ensinada nas salas de aula e apresentada nos livros didáticos pode ser lida a partir de duas formas narrativas distintas, que tenho denominado de história maior e história menor. Essa distinção se dá sob o aspecto da forma de expressão escolhida - um filme, um jogo, uma música, enfim, um recurso determinado que permita mostrar aos(às) estudantes o conhecimento histórico de um modo específico -, e sob o aspecto do recorte do passado que é tornado conteúdo a ser ensinado - uma revolução, um modo de produção, uma conjuntura política, uma história local - e que representa uma escolha com efeitos éticos importantes para se construir a aprendizagem histórica e a relação desta com o presente. Há, ainda, outro aspecto a ser pensado, que consiste na opção por uma narrativa descritiva e factual ou uma narrativa problematizadora e conceitual.

Este artigo realiza a opção pela história menor, não pela sua vã aparição em determinados momentos no planejamento anual do(a) professor(a), mas como uma prática política do currículo de História - ou seja, como um elemento que organiza e pensa as escolhas curriculares no que se refere aos recursos e formas de expressão bem como aos conteúdos e recortes no passado. Essa opção pela história menor se faz na crença de que inúmeros(as) professores(as) se põem a pensar e ensinar História fazendo escolhas que destoam da narrativa da história maior, que estão na contramão de uma narrativa eurocêntrica e sem corpo e privilegiam a história da pesca artesanal no entorno da escola ou a história da música como forma de resistência. São esses(as) professores(as) - dois deles denominados aqui de professor Melodia e professora Música - que fazem parte da vida e da voz deste artigo, que, junto a eles, quer falar e propor a militância por uma história menor.

\section{A HISTÓRIA MAIOR}

Por ora, preciso afirmar que o que chamo de história maior consiste numa narrativa baseada na descrição de grandes arranjos estruturais e sistêmicos, que conduz a constituição de esquemas explicativos de uma época e de um período determinado. Trata-se de uma narrativa estrutural, que recobre, em regra, tempos longos e descreve 
tempos contínuos e sequenciais, excluindo as descontinuidades e as diferentes alternativas que se apresentam a cada momento. A história maior é uma história sem corpo. Não é uma história do acontecimento nem das descontinuidades. Ela decorre de uma crença, notadamente eurocêntrica, de que um período, uma época, um momento histórico é comandado por uma lógica geral, por uma lei que determina a existência submissa dos acontecimentos a um modo único de organização (FOUCAULT, 1987). Ela tende, portanto, a descartar soluções alternativas, acontecimentos que se afastam da lógica geral e da lei de organização. Essa narrativa da história maior se revela como história "limpa", depurada da desrazão, do inexplicável, dos acontecimentos que rompem com as lógicas e fazem fendas nas estruturas. Desse modo, tem-se uma linha encadeada de fatos ou mesmo um processo que parece ter tido apenas as alternativas que aparecem com vencedoras na conjuntura estudada. É, portanto, uma história dos vencedores, 30 anos depois da crítica realizada a ela e da emergência da história dos vencidos.

Cabe lembrar o belo livro de Edgar De Decca (1981), 1930, o Silêncio dos Vencidos: memória, história e revolução, que se propôs pensar as alternativas do movimento operário para a Revolução de 30 , algo que dificilmente chegou à sala de aula e aos livros didáticos, pois nestes espaços a narrativa daquele acontecimento se limitava ao embate entre as forças da Aliança Liberal, das oligarquias dissidentes e a oligarquia paulista - a primeira representada por Getúlio Vargas, e a segunda, por Júlio Prestes. Essa narrativa era de uma história maior, de uma história que dava espaço, não obstante toda a crítica feita no âmbito da pesquisa sobre o ensino dessa disciplina, ao tempo contínuo e à história dos vencedores, aquelas forças dominantes que aparentemente tinham o controle da cena política. O Bloco Operário Camponês, lembrado e pesquisado por De Decca, continua esquecido. Assim, foi silenciada a luta operária e o papel desses grupos nos processos políticos do Brasil.

A lembrança de De Decca e do seu livro serve para que se possa continuar a conceituar o que chamo de história maior. Esta forma narrativa ainda é tão dominante que, como diria Quijano (2005), ainda faz parte de um discurso colonizado, que pensa o passado recortado pelos quadros definidos pelo eurocentrismo, uma história de grandes períodos, Idade Antiga, Média, Moderna e Contemporânea, situando todos os povos nessa linha evolutiva e excluindo para o campo do atraso aqueles estranhos às lógicas e as formas de organização características de cada período. Continua a ser uma história dos vencedores, ainda que as divisões sejam de modos de produção que se sucedem. 
A história maior é sempre contada como se fosse toda a História, pois the empresta uma lógica que permite ao estudante concluir que há identificação entre o passado e a História. Esta identificação esvazia a potencialidade do passado e limita o que dele se pode pensar ao que está escrito na forma de narrativa histórica, seja na sala de aula, seja no livro didático. Assim, tudo o que está fora dessa narrativa parece não ter história, nem passado, nem memória.

Entre os problemas mais comuns criados pela história maior está uma espécie de impossibilidade de memória e de história aos vencidos, às descontinuidades e aos desvios. Se pensarmos na memória, no seu caráter construído, na memória coletiva, no resultado das disputas e das negociações no campo social e político, verificamos que uma história maior se vale dessa grande memória, chamada de coletiva, ${ }^{1}$ e para ela se dirige, reforçando sua existência e diminuindo a possibilidade de sua reelaboração. Tudo se passa como se a história maior contada na escola fosse, ao mesmo tempo, num só movimento, escrita a partir das referências dessa grande memória e participante ativa do processo de cristalização e consolidação da memória coletiva. É assim que um modo de contar história na sala de aula e as escolhas e recortes do passado que lhe servem de objeto concorrem nas disputas e negociações da memória coletiva, integrando e dando estabilidade a crenças, visões e noções sobre o passado e o presente. A história maior leva ao silenciamento e a invisibilidade das memórias individuais, de grupos e de povos, que não são contempladas pela grande memória. Ela se preocupa em apresentar quatro revoltas regenciais - num quadro que destaca Cabanagem, Balaiada, Sabinada e Farroupilha, mas esquece da Guerra dos Malês - e faz isso de modo a construir uma lógica do período regencial que se caracterizaria pelo conflito centralização/descentralização, mas não consegue inserir um movimento liderado por negros muçulmanos. A razão disto é tanto a própria invisibilidade desse movimento na grande memória quanto o efeito que essa não inserção causa, que é justamente o início da conversa, o seu desvio em relação à memória nacional. É como se a história maior fixasse o olhar apenas numa linha, que é produto da colonialidade, ${ }^{2}$ uma vez que é progressiva e evolucionista, impedindo os

\footnotetext{
${ }^{1}$ Aqui, a memória coletiva se confunde com uma memória cristalizada de uma sociedade nacional, que se impõe e dificulta a emergência de outras memórias negligenciadas.

${ }^{2}$ Para Quijano (2005), a colonialidade do poder consiste num padrão de poder mundial que se constitui com o processo de colonização do século XVI e se estende até nossos dias, tendo como base a divisão racial do mundo e estabelecendo hierarquias entre os povos. "Na produção dessas novas identidades, a colonialidade do novo padrão de poder foi, sem dúvida, uma das mais ativas determinações. Mas as formas e o nível de desenvolvimento político e cultural, mais especificamente intelectual, em cada caso, desempenharam também um papel de primeiro plano. Sem esses fatores, a categoria Oriente não teria sido elaborada como a única com a dignidade suficiente para ser o Outro, ainda que por definição
} 
desvios, os acontecimentos, as vidas e os corpos de terem um lugar de memória ou fazendo com que seus lugares de memória sejam negligenciados pelos(as) estudantes.

Estuda-se, por exemplo, toda a Idade Média, toda a História de Santa Catarina, toda a História do Brasil, dividindo cada uma dessas histórias em períodos, em ciclos, todos dotados de uma lógica única. A Idade Média é dividida em Invasões Bárbaras, Auge do Feudalismo e Crise do Sistema Feudal. Essa forma de narrativa da Idade Média, em primeiro lugar, recolhe os acontecimentos e as experiências de vida medieval a cada um desses três momentos com suas formas únicas de organização, em segundo, desconhece e silencia outras experiências que parecem não se adequar a esses esquemas. Pode-se citar, por exemplo, a total invisibilidade em livros didáticos ou aulas de História da experiência da Igreja Cátara no sul da França. Do mesmo modo, pode-se ver que há uma impossibilidade de histórias escritas que tenham como objetivo (re)eleborar a memória e redefinir os parâmetros das nossas lembranças. É bem verdade que, como afirma Pollack ao referir Halbwachs, a memória coletiva não é impositiva, ou "uma forma específica de dominação ou violência simbólica". Ele afirma que Halbwachs "acentua as funções positivas desempenhadas pela memória comum, a saber, de reforçar a coesão social, não pela coerção, mas pela adesão afetiva ao grupo, donde o termo que utiliza, de "comunidade afetiva"' (1989, p. 03). Entretanto, Halbawachs trata de memórias coletivas de grupos específicos, que, através delas, constituem relações de pertencimento e afirmação afetivas e de autoestima. O caso que aqui apresento trata de uma memória nacional ou mesmo coletiva que recobre um espaço nacional ou o espaço global, como a memória ligada à colonialidade; portanto, o problema é bem outro. Não se trata de imposição, mas de uma adesão que se dá por meio dos diferentes lugares em que a memória é construída e reconstruída, como a escrita da História e a aula de História. É exatamente dessa maneira que queremos inserir a discussão sobre a história maior: ela constitui-se como parte de um processo complexo de construção de adesões, interpelações e constituições de subjetividades, que excluem e silenciam ao estabelecer parâmetros definitivos ao passado na forma de História. Essas adesões se dão, entretanto, na forma da metáfora do espelho utilizada por Quijano (2005), acentuando que, na maior parte das vezes, olhamos para nossa História a partir do espelho do eurocentrismo, que nos apresenta sua versão de nós mesmos. A tragédia, portanto, é construirmos uma noção de quem

inferior, de Ocidente, sem que alguma equivalente fosse criada para indios ou negros 9 . Mas esta mesma omissão põe a nu que esses outros fatores atuaram também dentro do padrão racista de classificação social universal da população mundial" (2005, p.121). 
somos desconsiderando a especificidade que pode nos constituir por fora desse espelho.

Assim a história maior é desprovida de corpo. Ao trabalhar no nível dos grandes acontecimentos e dos grandes esquemas explicativos, no registro de uma história total, ela descorporifica a História. Os presidentes, os reis, os sistemas, os modos de produção e mesmo as conjunturas não deixam insinuarem-se os corpos, as vidas cotidianas, os localismos, o movimento sensível da música, da dança, das lutas, das ocupações. A história maior é, nesse sentido, uma história da razão, de uma racionalidade que exclui o corpo, que supõe, desde a moderna filosofia, uma cisão entre corpo e espírito, entre razão e vida prática. Relegando o corpo e a vida prática a um plano inferior, donde a inconsciência e a desrazão seriam a norma, repete uma fórmula de racionalidade eurocêntrica que destrói os sentidos das formas diversas de conhecimento e de experiência de sujeitos e agentes não europeus, não brancos. Os saberes e as experiências de diversos povos estão desde já desprovidos de memória e de história. É o caso do tratamento dado às religiosidades afro-brasileiras, que raras vezes aparecem em aulas e livros didáticos de História, pois são parte de uma memória coletiva que lhes reserva o papel de mito e de seitas, são classificadas como não religiões.

Os efeitos de uma história maior são muitos e diversos. Além de constituir uma impossibilidade de memória e história para povos e grupos não brancos e não europeus, excluem do quadro da sala de aula também as histórias fragmentadas da vida prática, do corpo, dos vencidos, das lutas diárias e de uma gama de movimentos que não são classificados como História e que não aparecem no computo de uma grande memória. A história maior é uma história colonizada e colonizadora. É a história do colonizador. Mas, sobretudo, é parte do projeto da modernidade/colonialidade, que, como bem argumenta Quijano, constitui um padrão de poder em escala global que controla as formas de trabalho, a produção das subjetividades e as formas de conhecimento através de um esquema que hierarquiza as pessoas socialmente segundo os marcadores da raça, criando e reforçando uma condição natural de desigualdades (2005). Dessa forma, cria classificações binárias e hierárquicas que definem o branco e o não branco, a razão e os saberes tradicionais, a religião e o mito, o tradicional e o moderno, o primitivo e o civilizado.

Por vezes, somos levados a pensar que essa história maior não mais faz parte das salas de aula e dos livros didáticos de História. Um olhar mais desconfiado, contudo, poderia conduzir a crítica não apenas às estratégias novas e modernas, das 
tecnologias, das atividades lúdicas, mas à narrativa histórica que ensina sobre o passado e o presente e ao modo como essa narrativa situa diferentes sujeitos em diferentes lugares, silenciando sobre grupos, povos, movimentos identitários, indivíduos, diferenças, para, então, repensar essa narrativa e colocá-la sob suspeita de estar ainda no campo da naturalidade de um modelo eurocêntrico que indica o que é correto e como é adequado saber sobre o passado e o presente. É por isso que queremos pensar em termos de uma história menor.

\section{A HISTÓRIA MENOR}

Início esta parte pela experiência do(a) professor(a) aqui chamado de Melodia. Sua prática consiste num movimento de história menor, num relâmpago que rasga as estruturas e envolve a escola, os(as) alunos(as) e os outros(as) professores(as) num turbilhão de ações violentas contra a memória coletiva, disposto a narrar histórias pouco comuns com meios de expressão que param o tempo cronológico e dispõem os(as) alunos(as) na duração precisa de novas memórias e novas histórias. O professor Melodia decidiu realizar uma atividade interdisciplinar com a professora de Música da escola onde trabalha e escolheu, para o projeto, o tema da diversidade étnica do Brasil:

...nós decidimos fazer um trabalho sobre a diversidade étnica do país (...). Se encaixava dentro do que eu queria para a História; para ela, dentro de Música também estava tranquilo, era um tema que a interessava (...). (...) pretendemos fazer um trabalho sobre a diversidade étnica no Brasil, na formação do Brasil, trabalhando com grupos indígenas, grupos africanos e grupos europeus do período - a princípio seria com um período anterior à colonização, mas, depois, a coisa claro que extrapolou, né? Nós tivemos a adesão de, se eu não me engano, seis professores: professora do laboratório de Ciências, professora da sala informatizada, professora de Matemática, professor de Geografia, História, Música. Foram sete professores. E de Língua Portuguesa! Sete professores envolvidos. (professor Melodia)

O tema já não é tão incomum nas aulas de História da escola básica, mas o modo como o trabalho segue apresenta uma maneira muito singular de abordar a temática com o sexto ano. A presença da música funcionou como uma forma de expressão e disseminação de culturas e saberes que permitiu aos(às) estudantes deslocarem-se da mera aprendizagem com a inteligência e utilizarem-se da sensibilidade para que olhassem para o outro e exercessem um movimento de alteridade. 
Mais para o final, do meio para o final do ano, a gente precisou fazer os nossos ensaios. Eram duas turmas de sexto ano. A gente colocava as duas turmas dentro de uma sala de aula, e fazíamos os ensaios. E aí eles cantavam, tocavam os instrumentos. Se eu não me engano foram duas ou três músicas indígenas, de índios do Brasil; uma ou duas canções africanas e uma ou duas canções de origem europeia, composições folclóricas portuguesas. (professor Melodia)

A história menor se nutre dessa aula na qual os(as) alunos(as) cantam e tocam instrumentos, conhecem músicas indígenas, africanas e portuguesas, mas, sobretudo, se encontram com musicalidades estranhas e vinculadas a grupos historicamente subordinados.

Mas, antes disso, já trabalhava com patrimônio, sem usar o conceito. Trabalhei... a minha vida toda trabalhei com música popular, especialmente a história da música popular brasileira: desde o período colonial com batuques, umbigadas e tal, no período do Império com choros, lundus, maxixes e tal, e depois, a história do samba, no século XX. (professor Melodia)

A história menor, portanto, é uma forma narrativa que se volta para histórias pouco contempladas no movimento longo e lógico das estruturas. É uma narrativa que, distante de realizar uma longa descrição de um período, se ocupa das formas de expressividade dos corpos. A música e as musicalidades afro-brasileiras, indígenas e mesmo portuguesas que o professor Melodia utilizou fazem parte de uma história de acontecimentos, de descontinuidades, de desvios em relação a uma lógica que sempre é eurocêntrica e colonizada. Diferentemente dessa narrativa descritiva e sem corpo, sem sensações, sem sensibilidades, o trabalho com os batuques, umbigadas, choros, lundus e maxixes recupera uma narrativa do acontecimento, de algo que tem uma existência vital e transforma a história narrada em história viva. $\mathrm{O}$ ator central dessa narrativa da história menor é o corpo. A escola está acostumada a uma narrativa sempre de homens e mulheres sem corpo, uma história de abstrações (o governo, o plano econômico, o Rei, a Rainha, o Conde, o Modo de Produção Feudal, o Capital), que, não discordamos, são necessários operadores de sentido da escrita da História. Porém, essa história maior, que localiza os sujeitos na estrutura, nas classes, nos homens governantes ou não, torna jovens, mulheres, negros e indígenas não sujeitos de História e de memória, afinal são os homens não comuns, excepcionais, com dons e poderes especiais, que movimentam a História e realizam as transformações. A história menor é a história da resistência, pois todo acontecimento é um ato de resistir, neste caso, ao discurso colonizador. "O acontecimento é aquilo que remete a um verdadeiro reencontro com a alteridade, a um outro dinamismo, a uma primeira vez, à 
imanência de uma recepção plena e inteira" (DOSSE, 2013, p. 87). Ou seja, ao realizar uma aula com a música dos povos silenciados pela História oficial, o professor Melodia cria uma composição de forças que rasga as estruturas, compromete a conjuntura e redefine o que faz parte da memória coletiva, criando novas histórias. É o mesmo que pensar que, ao invés de reafirmar as virtudes da religião grega ou mesmo do cristianismo, o currículo do professor Melodia e de muitos outros irrompesse violentamente o banquete calmo e sonolento da história maior com um novo cardápio, do Candomblé, das religiões afro-brasileiras, com a Terra Sem Males dos Guarani, sem definir hierarquias ou supor que essas religiosidades seriam seitas e não religiões. Ao tornar o currículo esse lugar dos "sem-nome", dos esquecidos da narrativa histórica e da sala de aula, a história menor espalha novas composições de forças, energias vivas que criam lugares de pertencimento para milhares de jovens e lugares de memória para povos e grupos identitários.

Por meio desse movimento a aula de História se torna uma experiência, já que a história maior ensina por meio do caminho único da inteligência, definindo causas, descrevendo processos, indicando nomes e datas, a história menor permite aos(às) alunos(as) experimentar o acontecimento, partilhar saberes, aprender com o inusitado da experiência do outro. Num único movimento, há uma "empatia" com a vida, com o sofrimento e com a alegria de sujeitos históricos corporais e um "estranhamento" com o surpreendente do modo como o outro olha para o mundo, para a História, para a religião. Esse estranhamento engendra uma simpatia ${ }^{3}$ que persiste e, assim, permite aprender com o outro. A história menor, portanto, está comprometida com a formação ética de cada indivíduo, para quem ter uma experiência com o outro implica transformar a si mesmo e produzir-se com novas alternativas de vida e de futuro.

Essa história-acontecimento recupera e possibilita novas histórias e novas memórias, reconhecidas no âmbito de uma sociedade. Tudo se passa como se a noção de ter uma experiência com a História aprendida estivesse ligada a dois elementos centrais da aprendizagem histórica: em primeiro, a emergência de memórias subterrâneas, como dizia Pollak (1989), que irão forçar a transformação das memórias coletivas e nacionais, que se revelam como acontecimentos abalando a cristalização da memória, concedendo visibilidade e ação a grupos e povos antes silenciados; em

\footnotetext{
${ }^{3}$ No pensamento de Bergson, a simpatia, sin-pathos, não quer dizer acessar a essência do objeto, como se poderia supor a partir do platonismo, mas significa coincidir com a duração do outro e, desse modo, coincidir com o próprio ritmo da vida, logo, com o próprio tempo, condição de existência de tudo. "A intuição é a simpatia pela qual nos transportamos para o interior de um objeto para coincidir com o que ele tem de único e, consequentemente, de inexprimível.” (BERGSON, 1989, 134).
} 
segundo, a transformação dessas memórias subterrâneas em narrativa histórica, de tal forma que jovens negros, indígenas, pobres possam se ver pertencendo às salas de aula e às histórias do Brasil e da humanidade, afirmativamente. É assim que pertencimento e estranhamento se complementam, possibilitando um reconhecimento positivo da identidade e uma aprendizagem nova.

O professor Melodia descreveu, ainda, uma atividade que realizou com o PIBID ${ }^{4}$ e demonstrou uma preocupação com a história local, com o entorno da escola, na tentativa de dar historicidade ao cotidiano dos(as) alunos(as) e à vida do lugar.

E aí o nosso trabalho, ali, era com o foco principal na atividade econômica, que foi tradicional, durante muito tempo, na região da escola onde eu trabalho, e que vem entrando, a partir dos anos 1980, vem entrando em decadência. Então a gente estudou a pesca artesanal. Então esse trabalho, envolvendo a História local, e a memória das pessoas em torno, foi muito focado, nesses dois anos, na questão da pesca artesanal. Nós entrevistamos, inclusive, alguns pescadores locais e chegamos a levar essa história para sala de aula. Nós fizemos pesquisa, e tal, de toda a formação econômica e social do lugar. E aí utilizávamos os depoimentos dos entrevistados, também, como fonte histórica. (Professor Melodia)

Fizemos uma contextualização, falando da influência indígena, da influência africana, com a armação baleeira que existia ali próxima da nossa escola, dos povoamentos. Essa turma que trabalhou esse... em que foi trabalhado esse conteúdo, referente à pesca... porque, na verdade, não era sobre a pesca, né? Era sobre a história do lugar. E uma das atividades principais daquele... uma das atividades principais do local era, foi a pesca artesanal, como eu disse, até a década de 1980. (professor Melodia)

O tempo da história local, dos pescadores locais, da pesca artesanal, que caracteriza o entorno da escola e a vida cotidiana dos(as) alunos(as), não é o tempo dos longos períodos ou das transformações macropolíticas, mas o tempo da vida prática, diária, dos ritmos das formas de trabalho, das diversões, das práticas afetivas e culturais do local. Trata-se de reaver para a História esses grupos que sequer olham para si mesmos, que não constam em relatos que os mostrem ao mundo, modificando profundamente a imagem que têm de si. A história local é importante não apenas, como diz Melodia, "porque eu percebo que o interesse deles é maior", mas porque esse interesse tem relação com sua própria inserção na História, com a constituição de uma memória e de um pertencimento ao lugar. Decorre disso, na leitura de Melodia, o interesse dos(as) alunos(as) pelo trabalho:

\footnotetext{
${ }^{4}$ O PIBID é o Programa de Iniciação à Docência, da Capes, que, desde 2008, concede bolsas a estudantes da licenciatura, com o objetivo de qualificar a formação docente e a própria escola pública.
} 
Por quê? Imagino, né, porque eles conseguem discutir, ou conversar, com mais facilidade, com pessoas da família, com vizinhos, e tal. Muitas vezes, conseguem... Pô, estou falando lá da... Mostro uma imagem de um sujeito jogando uma tarrafa: o pai, o tio, sabem jogar tarrafa. Às vezes eles reconhecem a pessoa que está jogando: "Ah! Meu vizinho!", “Ah! $\mathrm{Eu}$ conheço aquela pessoa! É de tal lugar". Isso tudo cria uma certa empatia maior, por parte dos estudantes. (professor Melodia)

Essa empatia com os agentes da sua própria história é o que pode redefinir os lugares desses(as) estudantes no mundo, sua relação com o lugar, seu pertencimento a uma história que é sua, dos seus afetos, e que é também a História de Santa Catarina, do Brasil, da humanidade.

Do mesmo modo, a professora Música se pôs a trabalhar um tema da história local, mas também um tema que diz respeito à formação ética e cidadã dos(as) estudantes. Um tema como a agroecologia desvenda a prática de uma história menor na medida em que desperta o inusitado de uma aula de História que se prepara para ultrapassar os limites do debate sobre a propriedade da terra - tema importante e relevante -, da produção de soja, arroz e milho em larga escala, da cana na época da colonização do Nordeste, e se põe ao lado da historicidade dos agricultores de uma pequena cidade de Santa Catarina, chamada Santa Rosa de Lima. Este é o lugar onde os(as) alunos(as) irão, numa saída de campo, aprender sobre História e ambiente, sobre as histórias desses agricultores orgânicos, sobre comer bem e sobre agronegócio e seus efeitos na vida de cada um deles. É a agricultura familiar o foco do trabalho, entrando na aula de História como Alcebíades no Banquete de Sócrates, irrompendo sem trégua e com uma crítica voraz em favor da vida, do meio ambiente e da história dos pequenos, dos "sem-nome", dos invisíveis. Ao escrever essa história, a professora Música usa o passado para redefinir a memória, para inserir na memória nacional a agroecologia e a agricultura familiar.

Nos últimos anos, a gente tem trabalhado com agroecologia, então a gente procura pegar os conteúdos - e é um trabalho interdisciplinar, por isso que eu falo "a gente", porque é um trabalho coletivo mesmo; cada professor envolvido no projeto, ele vai trazer, por exemplo: eu, procuro tentar trazer a questão da terra; o Camilo, também, Estudos Latinoamericanos, ele vai trazer bastante a questão da terra, né, da propriedade de terra: o que é agronegócio, que implicação que isso tem para a agricultura familiar, para o pequeno produtor, para os povos indígenas. A gente pega, mais ou menos, o conteúdo do oitavo, e tenta ver o viés que a pesquisa, que pode contribuir para a pesquisa deles. (Professora Música)

Então, como é que funciona: a gente tem que trabalhar no... os professores definem o tema. A gente tem mantido o tema da agroecologia, e a gente tem mantido o vínculo com Santa Rosa de Lima 
por uma questão afetiva, porque a gente acabou, de tanto ir lá, a gente já gosta, já conhece os agricultores, já gosta, eles nos recebem bem pra caramba, assim. Então eles já têm a expectativa, assim, de receber as turmas. E também por uma questão política de... mostrar para eles de... trabalhar com eles um pouco de mostrar que o agronegócio, para o planeta, ele não é bacana, para a saúde ele não é bacana; para o trabalhador, que está lá no campo, ele não é bacana. Então a gente fez essa escolha. (Professora Música)

Há, portanto, uma redefinição de quem são os sujeitos da História. Desde a crítica realizada à História tradicional, nos anos 80 , o maior dos objetivos da aula de História foi o de tornar o aluno um sujeito da História. Isso implicava criar situações que permitissem aos(às) estudantes se olharem como sujeitos. Desde então, porém, ainda continuamos a contar uma história maior, que dava mais atenção a grupos majoritários, a movimentos estruturais e a grandes esquemas explicativos. Essa forma de narrar a História na sala de aula dificultava uma visibilidade aos(às) alunos(as), uma reconstrução de sua autoestima e a constituição de memórias que lhes permitissem pertencimento. O que vemos nas aulas do professor Melodia e da professora Música é justamente a ascensão de temas e de sujeitos invisíveis e silenciados que, ao aparecerem, criam relações de identificação e pertencimento e constituem relações de estranhamento que também levam à aprendizagem.

É nesse sentido que a história menor é uma história de resistência. Ela trabalha com memórias subterrâneas que vivem como rumores a incomodar a memória coletiva e majoritária; trabalha com histórias contadas em breves momentos em salas de aulas de inúmeros(as) professores(as) que rondam as histórias oficiais e dominantes, prontas a dar o bote e pular para a superfície a revolucionar os modos de dar aula, os temas e os objetos de ensino, mas também a vida e a organização da sociedade inteira. São forças que se abatem contra as estruturas e contras os ajustamentos momentâneos que tentam excluir grupos, ideias, pessoas, identidades, modos de vida. Essa história menor é um conjunto de forças de resistência: das vozes musicais dos indígenas, dos modos de vida dos agricultores familiares, das músicas de resistência dos negros, dos maxixes, dos lundus, dos pescadores. Uma aula de História assim constituída é um espaço aberto de forças, pois é exatamente aí que os(as) alunos(as) podem se reconhecer, se tornar pertencentes a uma memória e serem sujeitos de histórias. É nesse momento que alunos(as) se encontram com histórias nunca antes contadas, histórias de pessoas que eles pensavam não terem história, que estavam, talvez, encobertas pela vergonha de serem invisíveis. Pensemos no caso de tantos(as) alunos(as) que jamais se mostraram como pertencentes a uma religião como o 
Candomblé porque tinham vergonha de pertencer a algo que não fazia parte da memória majoritária, de algo que a pressão da memória oficial denunciava como seita, alguns até como agentes do mal. Isso ainda é comum em nossas escolas, e esses(as) alunos(as) acabam se sendo impedidos de sentir orgulho de sua religiosidade ou de seus pais.

A história menor é a história do Candamblé, das Candaces, das Work Songs. Ela envolve estudar como diferentes povos e grupos constroem alternativas para suas histórias e como essas forças de resistência se relacionam com as estruturas, com o Estado, com a grande política. A história menor conta, todos os dias, microrrevoluções que compõem modos de vida alternativos e resistentes. Por isso, ela é de outro tempo, assim como o professor Melodia e a professora Música.

\section{À Guisa de Conclusão: A temporalidade e a história menor}

De tanto estudarmos que a História da humanidade é dividida em Antiga, Média, Moderna e Contemporânea, acabamos por acreditar que essa divisão do tempo é natural e não fruto da invenção iluminista. Acreditamos mais: que a Revolução Francesa se constitui em um divisor da temporalidade de todos os povos, apresentando o estado adulto do homem branco europeu, moderno, em oposição aos povos originários, concebidos como "primitivos" e "atrasados". A concepção evolucionista do tempo concedeu ao branco europeu o lugar de destaque, mas conquistado com a força das armas, do genocídio e da dizimação de povos na América e, depois, da África e da Ásia. Nesse sentido, é que o eurocentrismo mapeou e organizou um modo pretensamente universal de viver e de conceituar o tempo. Esse modelo criou as ideias de evolução e de progresso supondo que o tempo consiste em uma linha que vai dos mais antigos e atrasados até os mais modernos e avançados. O tempo eurocêntrico é, então, um tempo cronológico, que dispõe a experiência humana num continuum, destruindo e desconhecendo temporalidades de experiências humanas estranhas ao tempo evolutivo. Em toda parte, esse modo de construir os relatos históricos foi adotado e, em função disso, ficaram de fora as narrativas de uma série de experiências e modos de vida. Essa linha evolutiva classifica, hierarquiza e cria toda a forma de preconceitos entre os povos e os grupos humanos.

Em oposição à ideia de evolução é que a história menor é Aion, porque se importa não em descrever e prender através da linguagem uma experiência que nasce, tem seu auge e morre, mas se preocupa com as durações de cada experiência, sem 
classificá-las na linha do continuum ou numa hierarquia de experiências. Em vez da linha, a história menor vê o tempo como labirinto e como rizoma, por onde as diversidades das durações não estão nem antes, nem depois, nem acima, nem abaixo, mas, quem sabe, num jogo de interferências. Desse modo, é possível contemplar as temporalidades e as experiências indígenas, africanas, juvenis e permitir que os(as) alunos(as) aprendam e se autotransformem com elas. Do mesmo modo, essa percepção do tempo possibilita uma leitura das injunções de um momento como resultado não de uma linha, mas de diversas alternativas que se apresentaram para compor o jogo de forças que vão constituir um novo momento.

Conclui-se, portanto, que a narrativa da história maior é sempre descritiva e factual, ainda que situada numa tendência crítica da História, enquanto a história menor constitui-se de uma narrativa problematizadora e conceitual. A primeira narra os esquemas explicativos e as estruturas; a segunda narra os acontecimentos e as experiências alheias. Acredito que tanto uma quanto a outra, por vezes, aparecem fortuitamente e sem nenhuma predefinição nas salas de aula e nos livros didáticos. Isso ocorre porque história maior e história menor não são modelos ou arquétipos ou mesmos tendências teóricas que possam ser escolhidas para todo o sempre. Também não são currículos formados, uma vez que os próprios currículos são campos de batalha e de disputa por narrativas. Elas são experiências de sala de aula e de modos de narrar a História que dependem, para existir, de diferentes formas de se usar o passado e de se realizar políticas narrativas no presente. Portanto, não se trata de sistemas ou de currículos fechados, mas estratégias escolhidas segundo posições de sujeito que professores(as) se inserem em diferentes momentos de seus fazeres e de seus saberes.

\section{Referências:}

BERGSON, Henri. Seleção de textos e tradução Franklin Leopoldo e Silva. São Paulo: Nova Cultural. Coleção Os Pensadores, 1989.

DE DECCA, Edgar Salvadori. 1930, o silêncio dos vencidos: memória, história e revolução. São Paulo: Brasiliense, 1981.

DOSSE, François. O renascimento do acontecimento: um desafio para o historiador - entre Esfinge e Fênix. São Paulo. Ed. UNESP, 2013.

FOUCAULT, Michel. A Arqueologia do saber. Tradução de Luiz Felipe Baeta Neves. $3^{\text {a }}$ Ed. Rio de Janeiro: Forense Universitária, 1987. 
POLLACK, Michael. Memória, Esquecimento, Silencio. Estudos Históricos, Rio de Janeiro, vol. 2, n. 3, 1989, p. 3-15.

QUIJANO, Anibal. A colonialidade do saber: eurocentrismo e ciências sociais. Perspectivas latino-americanas. Buenos Aires. CLACSO, Consejo Latinoamericano de Ciencias Sociales, 2005.

Recebido em: Set/2016

Aprovado em: Dez/2016 